British Journal of Psychiatry (1992), 161, 569-578

\title{
Correspondence
}

Editor: Ian Pullen

Contents: X-linked bipolar illness/Maternal viral infection hypothesis/Preconscious perceptual processing/Rapid tranquillisation/'Suicide prevention' by GPs/The cultural specificity of psychotherapy/ Effect of ECT on insulin/Reliability of DISCUS rating in individuals with learning disabilities/Evaluation in mental health care/Reporting predictable negative results/Hypnotising lobsters, etc./Stressinduced hallucinations/Koro and Capgras syndrome in a non-Chinese subject/Postnatal depression and antenatal morbidity.

\section{X-linked bipolar illness}

SIR: I read with interest the article by Hebebrand (Journal, January 1992, 160, 7-11) in which he suggests that evidence for X-linked dominant transmission of bipolar illness is lacking because he cannot find expected segregation ratios in the offspring of affected males in the pedigrees published in the literature. According to the author, this is mainly due to the fact that there are too few offspring of affected males for such analysis. (Female meioses are more informative for X-linkage studies, and in most linkage studies pedigrees are ascertained through doubly heterozygous females.)

I am therefore surprised that Dr Hebebrand can reach such a conclusion without actually being able to run a segregation analysis on the available data. $A$ segregation analysis is certainly warranted to test specific modes of transmission, but it cannot definitively prove or disprove a specific mode of transmission and it requires a much larger set of data (than small or medium-size pedigrees analysed for linkage) originating from the same population. Furthermore, Dr Hebebrand's appraisal of theoretical segregation patterns is based on the assumptions of full or high penetrance of the genotype and complete expressivity of the phenotype. These assumptions are not supported by twin, family and adoption studies (Mendlewicz, 1988).

Dr Hebebrand also does not take into account age distribution and risk period for the illness, or the plausible operation of other genes and interacting constitutional and environmental factors. The statement affected males should have a more severe illness than affected females under X-linked dominant transmission cannot be tested because such clinical data have not been reported in most linkage studies. Criteria for assessing severity of illness in affective disorders are not easy to define and many interacting factors, including environmental ones, may lead to large variability in phenotypic expression of the affective spectrum and render such naive analysis inconclusive in complex behavioural disorders. Also, a female to male sex ratio of affective illness of 2 to 1 should be looked for in epidemiological studies or in large samples of family studies but can not be expected from linkage studies using mainly relatively small pedigrees multiply affected and collected through unsystematic ascertainment. Furthermore, several linkage studies of affective disorder show a clear excess of affected females over males, an absence or rarity of male to male transmission, and segregation patterns consistent with a sex-linked inheritance (Rich et al, 1986). The fact remains that despite some negative findings, including some from our own group (Berretini et al, 1990; Van Broekhoven et al, 1991), there is now cumulative evidence from a majority of $\mathrm{X}$-linkage studies on a large number of pedigrees originating from several different geographical areas, substantiating the existence of an X-linked form of bipolar illness (Mendlewicz, 1992).

The frequency of the X-linked form of bipolar illness in the general population remains to be defined and non X-linked forms of the illness are most likely to be present, i.e. genetic heterogeneity occurs as is the case in most complex hereditary disorders.

Berettini, W. H., Goldin, L. R., Gelernter, J., el al (1990) Xchromosome markers and manic-depressive illness: rejection of linkage to Xq28 in nine bipolar pedigrees. Archives of General Psychiatry, 47, 366-373.

MENDLewiCZ, J. (1988) Population and family studies in depression and mania. British Journal of Psychiatry, 153 (suppl. 3), 16-25.

- (1992) New molecular genetic studies in affective disorders. Pharmacopsychiatry, 25, 29-32.

Rich, N., BARON, M. \& MendLEWICZ, J. (1986) Assessing the role of $\mathrm{X}$-linked inheritance in bipolar related major affective disorder. Journal of Psychiatric Research, 20, 275-288. 
Van Broekhoven, C., De Bruyn, A., Raeymaekers, P., et al (1991) Molecular genetic analysis in bipolar illness. Proceedings of the 5th World Congress of Biological Psychiatry, Firenze, June 9-14. Biological Psychiairy, 2, 452-454.

Cliniques Universitaires de Bruxelles

Route de Lennik 808

\section{$B-1070$}

Bruxelles

Belgium

AUTHOR's RePLY: I want to point out that we have submitted an additional paper that extensively deals with statistical evaluations of clinical data (sexdependent evaluations of reproduction rates, disease phenotypes, and mean ages of affected individuals) presented in eight studies favouring $X$-linkage of bipolar illness (Hebebrand \& Hennighausen, 1992). Our study will statistically substantiate my previous criticism of the positive $\mathrm{X}$-linkage studies (Hebebrand, Journal, January 1992, 160, 7-11). We also show that out of the total of 43 pedigrees analysed in these eight linkage studies, 20 pedigrees were ascertained through male index cases. Thus ascertainment has not mainly occurred through doubly heterozygous females as Dr Mendlewicz presumes.

Because the reproductive status of affected males has not been clearly indicated in any X-linkage study, all statistical analyses (including segregation analyses) must deal with incompletely presented data. These missing data are of the utmost importance for substantiating the assumed $\mathrm{X}$-linked dominant mode of inheritance. It is disappointing that Dr Mendlewicz has not addressed this core issue. My criticism could readily be rejected by the respective investigators by explaining whether the affected males have reproduced, how many offspring they have and what their sex and phenotype is.

I cannot agree more that twin, family and adoption studies do not support assumptions of "full or high penetrance of the genotype and complete expressivity of the phenotype". However, according to Mendlewicz et al (1979) this does not apply to $\mathrm{X}$-linked bipolar illness, which is characterised by a "high density of affective disorders in the relatives and by a strong penetrance of the gene as suggested by the early age of onset in some relatives". High penetrance rates have been assumed in all positive $X$ linkage studies. Mendlewicz et al (1987) have shown that the load score drops upon assumption of reduced penetrance rates. Is Dr Mendlewicz now suggesting that the assumption of a high penetrance rate in the $\mathrm{X}$-linkage studies was incorrect?
Concerning the elucidation of $\mathrm{X}$-linked dominant disorders such as classic Alport syndrome, considerable efforts were spent on the demonstration of the characteristic segregation patterns in pedigrees analysed for X-linkage (Atkin et al, 1988). Unfortunately, this has not been the case for the allegedly $\mathrm{X}$-linked dominant subgroup of bipolar illness. In historic terms, the assumption of $\mathrm{X}$-linked dominant inheritance was merely based on early findings of a preponderance of affected females and a paucity of male to male transmissions in bipolar pedigrees. Both of these findings appear controversial, since they were not clearly substantiated in later studies. In addition, psychiatric research has not concentrated on other features that characteristically apply to $\mathrm{X}$-linked dominant disorders. It appears as if formal genetics are not as important in psychiatry as in other medical fields.

It is quite surprising that Dr Mendlewicz considers unsystematic ascertainment. Were the ascertainment procedures in the $\mathrm{X}$-linkage studies systematic as suggested in the respective publications or were they not?

In conclusion, the formal genetic aspects urgently need clarification. This work cannot be done by myself or anybody else who has not identified an $\mathrm{X}$-linked bipolar pedigree.

Atkin, C. L., Hasstedt, S. J., Menlove, L., et al (1988) Mapping of Alport syndrome to the long arm of the $\mathrm{X}$ chromosome. American Journal of Human Genetics, 42, 249-255.

Hebebrand, J. \& Hennighausen, K. (1992) A critical review of clinical data presented in $\mathbf{8}$ studies favoring $\mathrm{X}$-linkage of bipolar illness with special emphasis on formal genetic aspects. Human Genetics (in press).

Mendlewicz, J., Linkowski, P., Guroff, J. J., et al (1979) Color blindness linkage to bipolar manic-depressive illness. Archives of General Psychiatry, 36, 1442-1447.

-, SEVY, S., BrocAs, H., et al (1987) Polymorphic DNA marker on $\mathrm{X}$ chromosome and manic depression. Lancet, $i, 1230-1232$.

Klinik für Kinder-und Jugendpsychiatrie

J. HEBEBRAND

Hans-Sachs-Strasse 6

$W-3550$ Marburg

Germany

\section{Maternal viral infection hypothesis}

SIR: The paper by Sham et al (Journal, April 1992, $160,461-466)$ concludes boldly that "our results indicate that exposure to influenza epidemics between the third and seventh months of gestation is associated with schizophrenia in adult life" and "The hypothesis that maternal viral infection is an important cause of schizophrenia can explain 